Clinica Médica

\section{QUAL 0 VALOR DO BNP NA PRÁTICA CLÍNICA EM PACIENTES COM INSUFICIENNCIA CARDÍACA?}

O BNP (Brain natriuretic peptide) é um neurohormônio secretado pelos ventrículos em resposta à expansão de volume e sobrecarga de pressão. Seus níveis estão correlacionados com medidas hemodinâmicas, tais como: pressão átrio direito, pressão capilar pulmonar e a pressão diastólica final do ventrículo esquerdo.

Os níveis normais de BNP variam de 0 a $70 \mathrm{pg} / \mathrm{ml}$. Interpretações do resultado devem incluir considerações sobre idade e sexo, sendo os maiores valores no sexo feminino e quanto maior a idade. Os valores também estão elevados nos pacientes com insuficiência renal.

As medidas dos níveis de BNP têm um elevado valor preditivo negativo (98\%), sugerindo que pacientes com níveis de BNP normais, muito provavelmente, não apresentem disfunção ventricular. Portanto, o BNP tem sido considerado um marcador bioquímico atrativo e interessante para a triagem diagnóstica, avaliação do tratamento e prognóstico de pacientes com insuficiência cardíaca congestiva.

Os níveis de BNP permitem objetivar parâmetros clínicos, como a classificação funcional da NYHA. Pacientes em classe funcional I apresentam média de (I52 \pm 16 $\mathrm{pg} / \mathrm{ml})$, os de classe ll ( $332 \pm 25 \mathrm{pg} / \mathrm{ml})$, os de classe III $(590 \pm 3 \mathrm{l} \mathrm{pg} / \mathrm{ml})$ e os de classe IV $(960 \pm 34 \mathrm{pg} / \mathrm{ml})$.

Estudos dos níveis de BNP, em conjunto com outras informações clínicas, têm auxiliado no diagnóstico diferencial de pacientes com dispnéia de origem cardíaca daqueles de origem pulmonar. Morrison e colaboradores observaram níveis estatisticamente significantes $(758,5 \pm 798 \mathrm{pg} / \mathrm{ml})$ nos pacientes com dispnéia secundária à insuficiência cardíaca quando comparados àqueles de origem pulmonar $(6 \mathrm{I} \pm 10 \mathrm{pg} / \mathrm{ml})$.

Em pacientes com função sistólica normal, a elevação dos níveis $(286 \pm 31 \mathrm{pg} / \mathrm{ml})$ pode também reforçar o diagnóstico de disfunção diastólica em conjunto com as alterações ecocardiográficas. Pacientes com função sistólica e diastólicas normais apresentaram valores de BNP em média de $33 \pm 3 \mathrm{pg} / \mathrm{ml}$.

Pacientes submetidos a transplante cardíaco apresentam níveis elevados a despeito da normalização das pressões de enchimento e ativação do sistema renina-angiotensina e simpático. Estes níveis (> $400 \mathrm{pg} / \mathrm{ml}$ ) se correlacionam com o grau de rejeição e com os achados histológicosà biópsia endomiocárdica.

A estreita correlação do grau de ativação do BNP e a condição clínica cardíaca permite sua utilização na otimização do tratamento medicamentoso da insuficiência cardíaca. Estudos clínicos demonstram que esta abordagem é superior a terapêutica clínica empírica convencional.

Outra vantagem da utilização deste marcador está na avaliação da morbidade da insuficiência cardíaca: os pacientes que evoluíram satisfatoriamente após compensação clínica tiveram níveis menores $(500 \mathrm{pg} / \mathrm{ml})$ na alta hospitalar. Por outro lado, aqueles que apresentavam níveis superiores a $1000 \mathrm{pg} / \mathrm{ml}$ eram mais propensos a uma maior mortalidade ou chance de readmissão hospitalar num período de 30 dias.

Outro marcador que tem mostrado resultados semelhantes ao BNP é a dosagem do fragmento terminal do pró-BNP (NT-proBNP).

Acreditamos que estes marcadores bioquímicos serão utilizados de rotina na prática cardiológica. Este deve ser mais um método complementar, cuja função não é de substituir decisões clínicas, porém auxiliar o diagnóstico, terapêutica e estratificação prognóstica.

Fábio fernandes

Charles Mady

Referências

I. Maisel A.B-type natriuretic peptide levels: a potencial novel "white count" for congestive heart failure. Card Fail 200I; 7(2): 183-93.

2. Latini R, Masson S, Angelis N, Anand I. Role of Brain natriuretic peptide in the diagnosis and management of heart failure: current concepts. J Card Fail 2002:8(5):288-99

3. Lemos JA, McGuire DK. B-type natriuretic peptide in cardiovascular disease. Lancet 2003; 361:I-7.
Emergência e Medicina Intensiva QUAL A IMPORTÂNCIA DOS ANÁLOGOS DA INSULINA NO \section{MANEJO DO PACIENTE DIABÉTICO NA EMERGÊNCIA?}

Por que foi necessária a síntese de análogos da insulina?

Para permitir a reposição fisiológica da insulina por via subcutânea, no estado de jejum, assim como durante as mudanças dinâmicas das suas necessidades após as refeições.

Uma barreira para tal reposição tem sido a farmacologia das insulinas regular e NPH administradas por via subcutânea. Por exemplo, fisiologicamente após uma refeição, o pico de insulina ocorre em 30 minutos com retorno ao basal em 2 horas. Com a insulina regular o pico é em 2 a 4 horas e duração de 6 a 8 horas (ou até mais com doses maiores).

Quais são os análogos de ação rápida?

Insulina Lispro (Humalog- Lilly), sintetizada pela troca dos aminoácidos prolina e lisina nas posições B28 e B29 para lisina e prolina. Tem início de ação em 15 minutos, pico em I hora e duração de 3 a 5 horas. É, portanto, duas vezes mais rápida no início de ação, produz o dobro de pico de concentração de insulina e tem metade da duração da insulina regular, sendo eficaz em reduzir as elevações da glicemia pós-prandial. Outra opção com características semelhantes éa insulina Aspart (NovoRapid - Novo Nordisk) feita pela substituição da prolina da posição B28 por ácido aspártico, o que gera meia-vida um pouco mais longa que a Lispro.

Quais as principais vantagens dos análogos rápidos?

Ideais paraas refeições, particularmentericas em carboidratos e pobre em gorduras. Similar a regular, são absorvidas mais lentamente no deltóideeáreafemoral, resultando maior duração deação. Oinício deaçãoentretantonãoéalterado pelos diferentes sítios anatômicos de injeção, como ocorre com a regular e, devido sua curta duração, resulta em menor variabilidade na concentração sérica da insulina do que com a regular.

Por que sintetizar análogos de longa ação?

A homeostase da glicose nos períodos interprandial e noturno é finamente regulada 
por uma secreção lenta e contínua de insulina, situação que até agora só poderia ser mimetizada pela infusão contínua de insulina, já que as insulinas NPH, Lenta e Ultralenta apresentam picos. Tal feito é conseguido com a insulina Glargina ( Lantus - Aventis ) produzida por tecnologia de DNA recombinante através de duas modificações: troca da asparagina por glicina na posição A2 I eadição de duas moléculas de arginina na porção amino terminal da cadeia B. Tem início de ação em 2 a 4 horas, não produz pico edura pelo menos 24 horas. Hipóteses preliminares de que com o seu uso haveria mais retinopatia e mitogenicidade não foram confirmadas. Comparando com a NPH, gerou glicemias de jejum menores, menos episódios de hipoglicemia e menor ganho de peso.

O uso otimizado seria Glargina na hora de dormir e Lispro às refeições.

Qual o papel dos análogos de insulina nos quadros emergências?

$\mathrm{Na}$ cetoacidose diabética e na descompensação hiperosmolar deve-se continuar usando insulina regular intravenosa ou intramuscular, e somente após a compensação inicial, quando o paciente estiver se alimentando, pode-se optar por Lispro ou Aspart para cobrir as refeições (o que habitualmente é feito pela regular) e Glargina para manter a insulinemia basal (o que habitualmente é feito pela NPH ou Lenta), sempre por via subcutânea.

Paulo Roberto Corrêa Hernandes

Leituras recomendadas

I. Buse BB. Insulin analogues. Curr Opini Endocrinol Diabetes 2001;8:95-100.

2. Bolli GB, Owens DR. Insulin glargine. Lancet 2000; 356:443-5.

3. Hirsch IB, Farkas-Hirsch R. Intensive treatment of type I diabetes. Med Clin North Am 1998; 82:689-719.

\section{Ginecologia}

\section{A VIDEOLAPAROSCOPIA DEVE} SER USADA ROTINEIRAMENTE NA AVALIAÇÃO DO CASAL INFÉRTIL?

A propedêutica básica do casal infértil inclui a avaliação das tubas uterinas, que pode ser feita através da histerosalpingografia
(HSG), videolaparoscopia (VLP) e histerossonografia. Tradicionalmente, a HSG é inicialmente realizada permitindo não só a avaliação da permeabilidade tubárea como também da cavidade uterina. A VLP, por sua vez, é um método superior na detecção de patologia tubo-peritoneal, além de possibilitar a combinação do procedimento diagnóstico com o terapêutico em um mesmo tempo cirúrgico. Apresenta limitações, todavia, na avaliação da obstrução tubárea proximal e de aderências intratubáreas.

Não parece haver dúvidas quanto à necessidade de se realizar a VLP sea HSG encontra-se alterada, mas não está estabelecida a sua utilidade na presença de HSG normal. Alguns autores indicam a VLP para excluir a existência de aderências peritubáreas e endometriose, reduzindo-se desta forma a incidência de esterilidade sem causa aparente (ESCA) de $10 \%$ para $3,5 \%$.

A literatura mostra que na presença de uma HSG normal, a probabilidade de se encontrar uma alteração tubárea relevante ou um grau de endometriose que necessite tratamento é tão baixa que a VLP se faz desnecessária. Se os resultados da HSG são suspeitos, a VLP revelará alterações em mais de 2/3 dos casos com mais da metade apresentando doença pélvica moderada à grave. Na presença de uma HSG anormal, a probabilidade de se encontrar alterações a VLP sobe para $93,5 \%$, sendo $81,7 \%$ dos casos de acometimento pélvico moderado à grave.

Alguns autores sugerem a classificação das pacientes, conforme sua história pregressa, exame ginecológico e duração da infertilidade, em grupos de baixo e alto risco. Recomenda-se no grupo de alto risco (história prévia de doença inflamatória pélvica ou cirurgias pélvicas exame pélvico alterado e HSG suspeita ou anormal) a VLP deve ser incluída na avaliação inicial, podendo ser postergada nas pacientes de baixo risco.

Parece lógico, desta forma, propor algumas questões antes de se indicar uma VLP:

I. Qual a probabilidade de se encontrar uma alteração?

2. Que alterações podem ser previstas?

3. O cirurgião possui habilidade/competência para corrigir alterações porventura existentes?
4. A correção da(s) patologia(s) existentes afeta o prognóstico da paciente e/ou o tratamento proposto?

\section{Márcia Mendonça Carneiro \\ Aroldo fernando Camargos}

\section{Referências}

I. Petrozza, JC. The role of diagnostic laparoscopy in evaluation of infertility. Infertil Reprod Clin North Am 1997;8:327-35.

2. Evidence-Based Reproductive Medicine in daily practice. American Society for Reproductive Medicine. Annual Meeting Post-graduate Program. Orlando; 200I.

3. Fatum M, Laufer N, Simon A. Investigation of the infertile couple: should laparoscopy be performed after normal hysterosalpingography in treating infertility suspected to be of unknow origin? Hum Reprod 2002; 17:I-3.

\section{Medicina Zaseada em Euidencias \\ CORTICÓIDE PARA TODAS AS MENINGITES?}

A taxa de mortalidade e as seqüelas neurológicas entre pacientes adultos com meningite bacteriana, especialmente a meningite pneumocóccica, continuam altas, mesmo com a utilização de terapia antimicrobiana adequada e com a esterilização liquórica em 24-48 horas. $O$ que fazer para mudar esse panorama assustador?

Gans eVan de Beek realizaram um estudo sobre $\mathrm{o}$ uso da dexametasona na meningite bacteriana no adulto. Esse estudo clínico multicêntrico, prospectivo, randomizado, duplocego, utilizou em 157 pacientes dexametasona $10 \mathrm{mg}$ endovenoso de $6 / 6$ horas durante 4 dias e no outro grupo de 144 pacientes, um placebo, com o objetivo de avaliar a evolução neurológica dos pacientes com meningite bacteriana por um período de oito semanas. O corticóide era administrado I5-20 minutos antes ou concomitante à infusão do antibiótico para o tratamento da meningite.

Os resultados foram muito interessantes, demonstrando uma diminuição de mortalidade nos pacientes com meningite bacteriana aguda, que receberam dexametasona, com maior benefício para os pacientes com meningite pneumocóccica. Para meningites por 